\title{
The Structure and Properties of Ceramics, Obtained from Mixtures of the System $\mathrm{ZrO}_{2}-\mathrm{Al}-\mathrm{C}$
}

\author{
S.I. Dzhelialov \\ Department of Electromechanics and Welding, Crimean Engineering-Pedagogical University \\ named after F. Yakubov, Simferopol, Russia \\ dzhelyalov@mail.ru
}

Keywords: Ceramic Materials, Cutting Ceramic, Zirconium Oxide, Aluminum, Carbon, Hardness, Strength, Hot Pressing, Structural Analyses

\begin{abstract}
The paper presents the results of the analysis of the structures of materials obtained as a result of hot pressing of mixtures of the $\mathrm{ZrO}_{2}(\mathrm{~m})-\mathrm{Al}-\mathrm{C}$ system of various compositions. The nature of the change in the composition and physical and mechanical properties of the obtained materials was established depending on the concentration of aluminum and carbon in the initial mixture, as well as the parameters of hot pressing.
\end{abstract}

\section{Introduction}

The potential of the materials with which a metal-cutting tool is equipped is one of the key indicators that determine the quality and productivity of cutting processes. The constant expansion of the range of difficult-to-machine structural alloys and the need to increase cutting speeds entails the need to create new types of metal-cutting materials. In the traditional hierarchy of the latter, the class of mineral ceramics (ceramics) occupies its own niche, distinguished by its ability to provide high-speed finishing and semi-finishing of most structural alloys, including difficult-tomachine alloys. At the same time, ceramics are distinguished by their ability to most effectively resist chemical-thermal and adhesion processes occurring on the cutting edge of the tool during processing. A lot of research carried out by scientists from different countries [1-11] indicates the prospects for the development of these types of materials. It should be noted that in a number of works, researchers pay attention to eliminating one of the most important disadvantages of tool ceramics - reduced crack resistance.

The results of studying the regularities of the formation of the structure and properties of materials synthesized from powder mixtures of the $\mathrm{ZrO}_{2(\mathrm{~m})}-\mathrm{Al}-\mathrm{C}[12,13]$ system showed that it is promising for creating a material for instrumental purposes. The purpose of this work is to study the structure and phase composition of materials obtained by hot pressing (HP) from mixtures of this system and to establish the nature of their change depending on the concentration of aluminum and carbon in the initial mixture, as well as the parameters of hot pressing.

\section{Experimental technique}

When preparing a mixture to obtain a cutting ceramic material, we used powders of monoclinic zirconium dioxide produced by SRPE «Tsirkonii» (Dneprodzerzhinsk, Ukraine), manufactured according to TUU 14-10-098-99, and PAP-4 grade aluminum powder (GOST 5494-71) and lamp black grade S-1 (GOST 18307-78).

The levels and intervals of variation of factors accepted in the study, which correlated with the results of works $[12,13]$, are shown in Table 1. 
Table 1. Levels and intervals of variation of factors

\begin{tabular}{|c|c|c|c|c|c|c|}
\hline \multirow[t]{2}{*}{ Factors } & \multirow{2}{*}{$\begin{array}{c}\text { Variations } \\
\text { Interval }\end{array}$} & \multicolumn{5}{|c|}{$\begin{array}{l}\text { Natural levels of factors } \\
\text { corresponding to the coded }\end{array}$} \\
\hline & & +2 & +1 & 0 & -1 & -2 \\
\hline \multicolumn{7}{|c|}{ The concentration of the initial components of the mixture, wt \% } \\
\hline $\mathrm{C}$ & 1 & 2,5 & 3,5 & 4,5 & 5,5 & 6,5 \\
\hline $\mathrm{Al}$ & 2,5 & 16 & 18,5 & 21 & 23,5 & 26 \\
\hline \multicolumn{7}{|c|}{ Hot pressing process parameters } \\
\hline $\mathrm{P}, \mathrm{MPa}$ & 3 & 18 & 21 & 24 & 27 & 30 \\
\hline $\mathrm{T},{ }^{\circ} \mathrm{C}$ & 60 & 1400 & 1460 & 1520 & 1580 & 1640 \\
\hline Isothermal holding time, $\tau$, min & 5 & 5 & 12 & 19 & 26 & 33 \\
\hline
\end{tabular}

The milling and mixing of the initial charge was conduct in a steel drum lined with hard alloy plates on a roller table. Carbide balls with a diameter of 10-12 $\mathrm{mm}$ were used as grinding solids. The portions of powder mixtures were pre-briquetted (cylinders with a diameter of $19 \mathrm{~mm}$ ) and placed in a graphite mold with a cylindrical working chamber with a diameter of $20 \mathrm{~mm}$, after which it was installed in the working zone of copper high-frequency current inductors. The hot pressing of prototypes was conduct on a unit equipped with a thyristor frequency converter of the ТПЧТ-120 type. To measure the heating temperature during hot pressing, a PPT-131 pyrometric transducer was used.

The hardness of the obtained samples was measured according to Vickers $\left(\mathrm{HV}_{15}\right)$ on a TP-2 hardness tester at a load of $15 \mathrm{kN}$ and holding under load for $10 \mathrm{~s}$ (GOST 25172-82). Palmquist fracture toughness $\left(\mathrm{K}_{1 \mathrm{c}}\right)$ of the materials was determined on indentations obtained by indentation with a Vickers pyramid according to the method described in [14].

Metallographic studies of the structure of the obtained materials, their photographing were performed on a metallographic microscope "METAM-P1" manufactured by "LOMO", equipped with a digital video camera, in reflected light.

Fractographic studies in this work were performed using the method of scanning electron microscopy on an analytical field emission scanning electronic microscope "EVO 50XVP" (CarlZeiss). Detection and analysis of X-rays was performed using an X-ray energy dispersive spectrometer «INCA Penta FET-x3».

\section{The discussion of the results}

The results of work [12], which were performed in accordance with the intervals of variation presented in the Table 1, showed that the most pronounced effect on the structure of hot-pressed materials is exerted by a change in the concentration of carbon in the initial mixture.

In the Fig. 1 shows typical types of the structure of samples obtained by HP of mixtures of the composition $\mathrm{ZrO}_{2}-21 \mathrm{Al}-6.5 \mathrm{C}$ and $\mathrm{ZrO}_{2}-26 \mathrm{Al}-4.5 \mathrm{C} \%$ (wt \%). The first composition assumes the maximum possible carbon content in the initial charge from the specified variation intervals, the second assumes the maximum possible aluminum content (the corresponding carbon and aluminum concentrations are in the center of the variation interval). The Fig. 1, a shows that the phases included in the material structure obtained from a mixture of $\mathrm{ZrO}_{2}-21 \mathrm{Al}-6.5 \mathrm{C} \%$ (wt \%) are unevenly distributed in the volume of the material.

According to the results of metallographic studies, materials obtained from mixtures of $\mathrm{ZrO}_{2}(\mathrm{~m})$ $-18.5 \mathrm{Al}-3.5 \mathrm{C} \%(\mathrm{wt} \%)$ at a hot pressing pressure of $21 \mathrm{MPa}$ have a structure containing local pore clusters and loose areas (Fig. 2, a). 


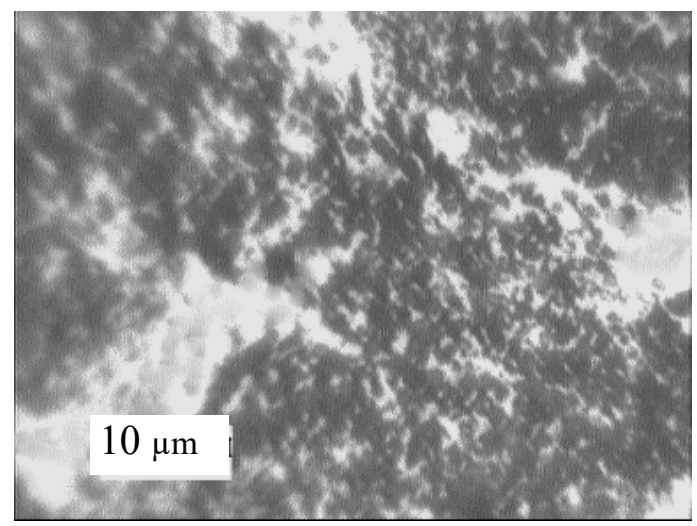

$\mathrm{a}$

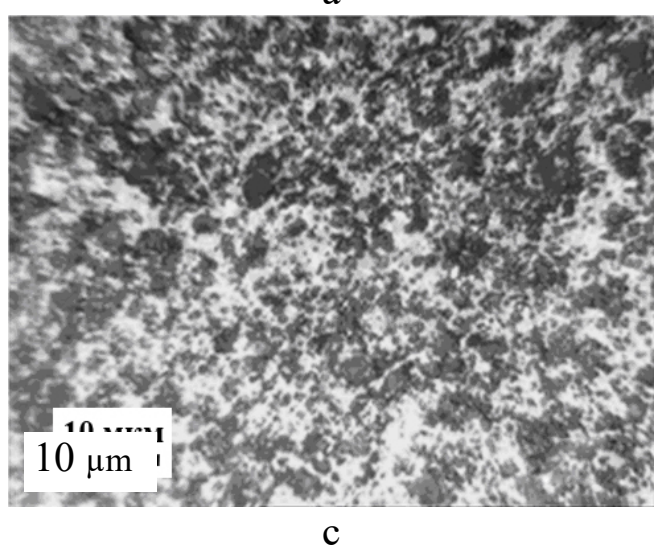

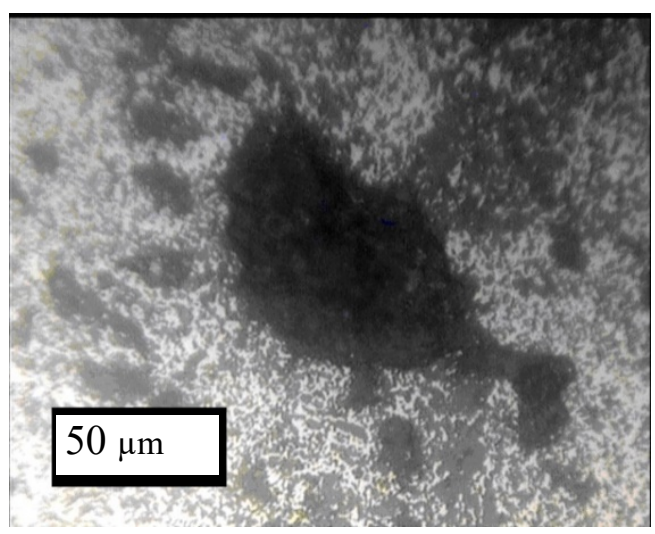

b

Fig. 1. The structure of materials obtained by hot pressing mixtures: $a, b-\mathrm{ZrO}_{2}-21 \mathrm{Al}-6,5 \mathrm{C}$; $c-\mathrm{ZrO}_{2}-26 \mathrm{Al}-4,5 \mathrm{C} \%(w t \%)$.

The sizes of phase inclusions, considering the large grains, are in the range of $0.5-20 \mu \mathrm{m}$. The specified wide range of grains size creates a wide range of hardness values $\left(\mathrm{HV}_{15}=18,7_{-1,5}^{+0,5} \mathrm{MPa}\right)$ in the volume of the material. Also, in this structure, defects in the form of large pores are observed (see Fig. 1, b). The reason for the formation of pores can be the low compressibility of the sample due to the high carbon content in the initial powder mixture.

The structure of materials obtained from a mixture of the composition $\mathrm{ZrO}_{2}-26 \mathrm{Al}-4.5 \mathrm{C} \%$ (wt \%) is distinguished by a significantly more uniform distribution of phase components and a defect-free structure, while the range of grain sizes is limited by narrower limits: $2-5 \mu \mathrm{m}$ (Fig. 1, d). Taking into account the fact that the parameters of hot pressing for the considered mixtures were at the same level, the effect of an increase in the concentration of aluminum in the initial charge becomes obvious. At the same time, the relatively low hardness values of samples obtained from a mixture of the composition $\mathrm{ZrO}_{2}-26 \mathrm{Al}-4.5 \mathrm{C} \%$ (wt \%) (on average $\mathrm{HV}_{15}=17.7 \mathrm{MPa}$ ) are probably caused by the presence of intermetallic inclusions in its structure, the formation of which is characteristic of this system. (see the example in Fig. 3).

In Fig. 2 shows the structures of materials obtained from a mixture of $\mathrm{ZrO}_{2}(\mathrm{~m})-\mathrm{Al}-3.5 \mathrm{C} \%$ (wt $\%$ ), with different -18.5 and $23.5 \%$ (wt \%) aluminum content. It can be seen from the figure that, despite the differences in the $\mathrm{Al}$ content in the initial mixture, the grain size of the presented materials differs insignificantly (Fig. 2, c, f) and is in the range of $0.5-2 \mu \mathrm{m}$. In accordance with the data [12], an increase in the hot pressing pressure to $27 \mathrm{MPa}$ leads to a decrease in the volume of the above-mentioned structural defects. However, the presence of randomly located single pores throughout the sample volume (Fig. 2, b, d) indicates that this is not enough for the formation of a continuous non-porous structure. This disadvantage is absent in materials obtained from mixtures 
of $\mathrm{ZrO}_{2(\mathrm{~m})}-23.5 \mathrm{Al}-3.5 \mathrm{C} \%$ (wt \%). It is indicates that an increase in the aluminum content to $23.5 \%$ (wt \%) improves the compressibility of the samples. and contributes to the formation of practically non-porous structures (Fig. 2, e).

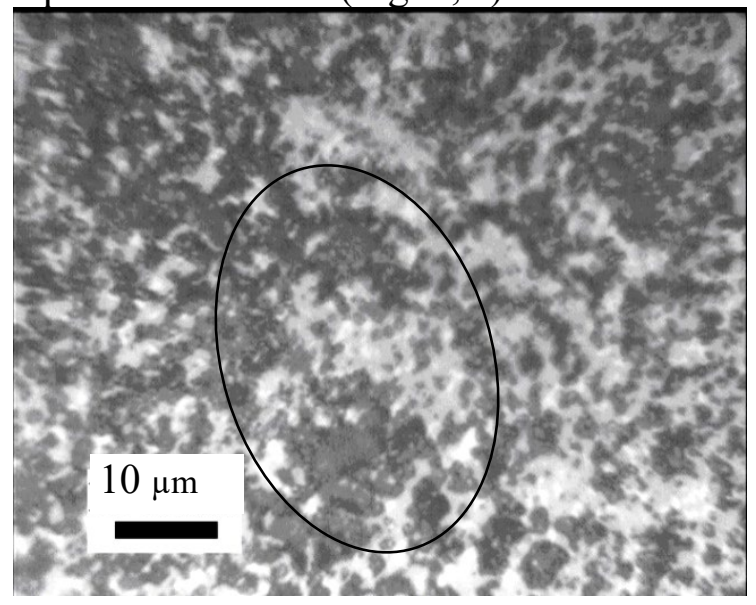

a

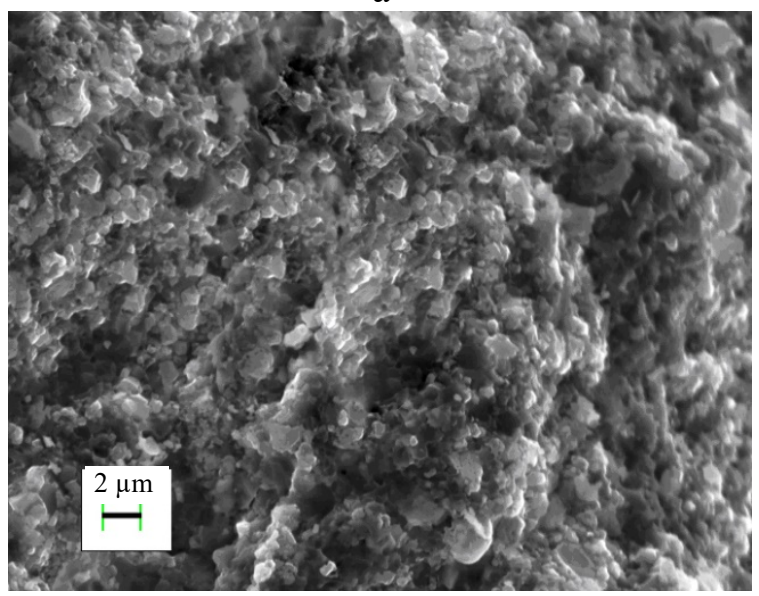

c

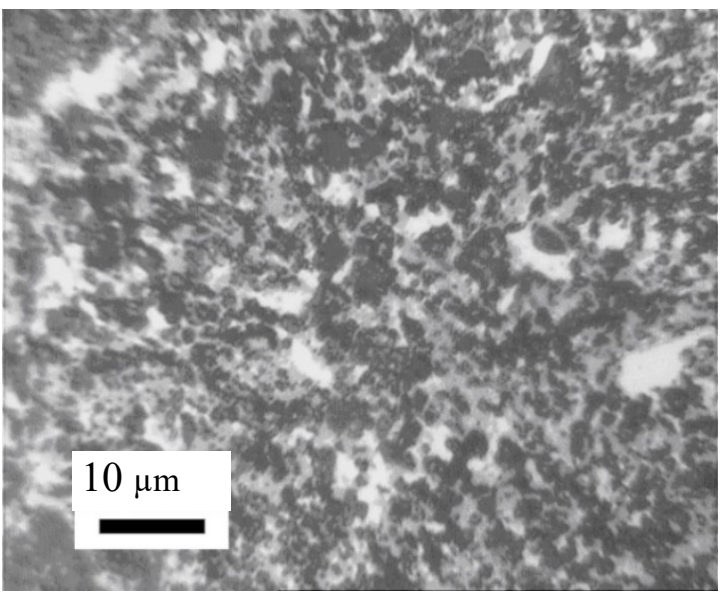

e

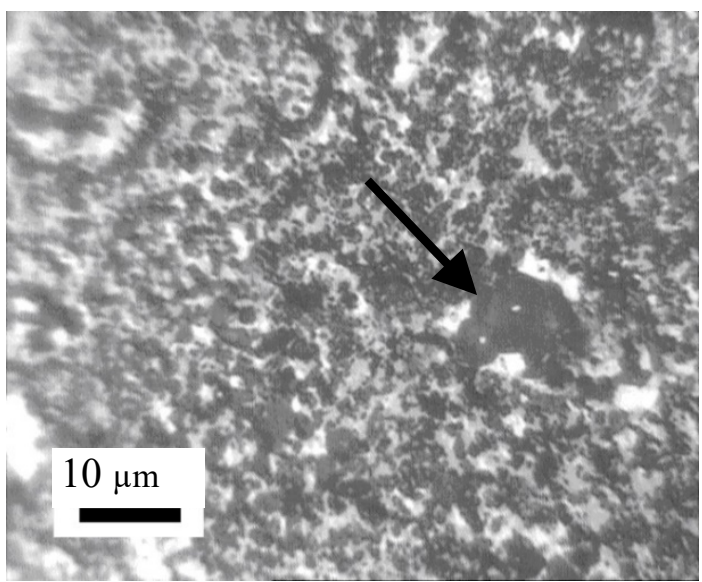

b

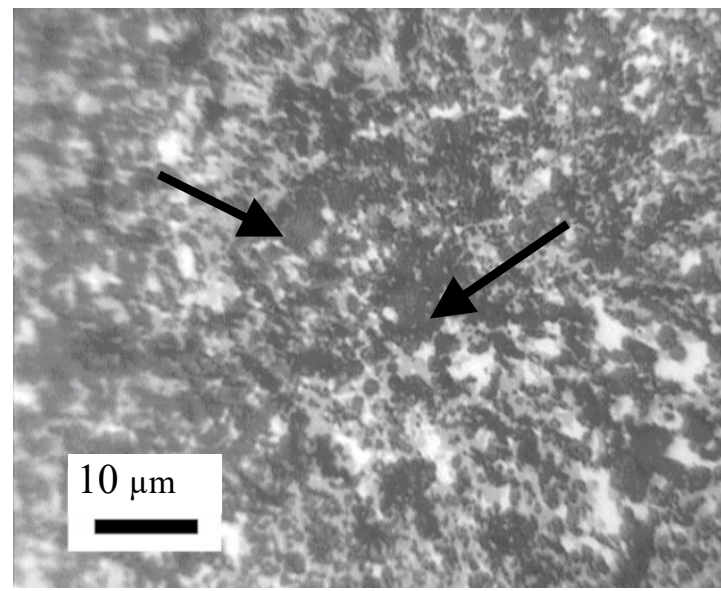

d

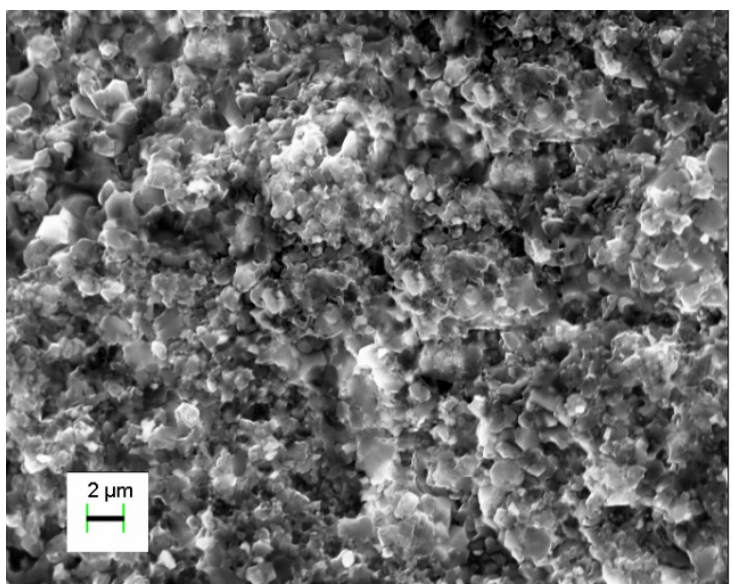

f

Fig. 2. The structure of materials obtained by hot pressing a mixture of $\mathrm{ZrO}_{2(m)}-\mathrm{Al}-3.5 \mathrm{C} \%$ $(w t \%)$, with different content of aluminum in the initial mixture $(\% w t \%): a, b, c, d-18.5$; e, $f-23.5 ; a-$ at $P=21 \mathrm{MPa} ; b, d-$ at $P=27 \mathrm{MPa}$. 
At the same time, it should be consider that an increase in the content of aluminum in the composition of the initial mixture also leads to an increase in the number of compounds based on it in the structure of hot-pressed samples. In Fig. 3 shows the distribution of elements in the structure of a hot-pressed material, from a mixture of $\mathrm{ZrO}_{2}(\mathrm{~m})-23.5 \mathrm{Al}-3.5 \mathrm{C} \%$ (wt \%), obtained as a result of X-ray microanalysis.

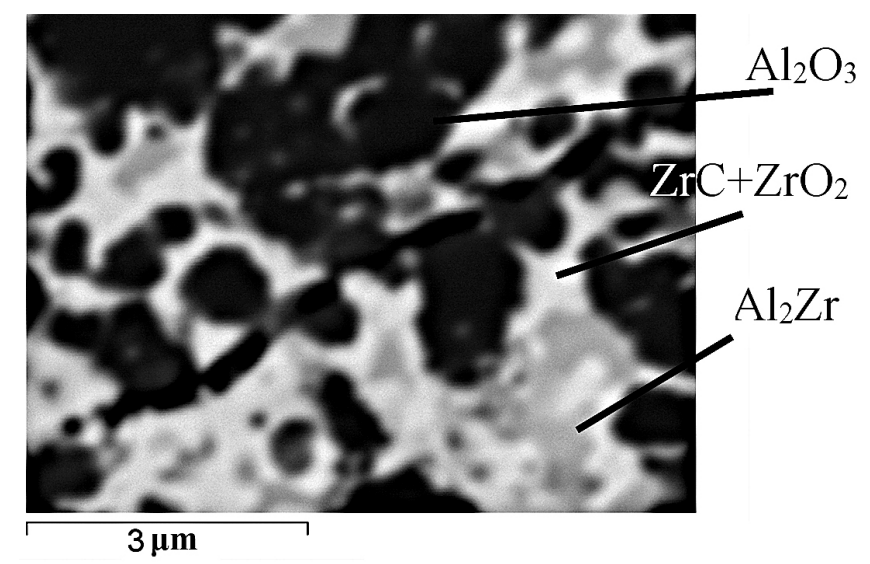

Fig. 3. Microstructure of a thin section in phase contrast (a) of a hot-pressed sample obtained at $T=1500^{\circ} \mathrm{C}, \tau=10$ min, $P=24 \mathrm{MPa}$ from a mixture of $\mathrm{ZrO}_{2(m)}-23.5 \mathrm{Al}-3.5 \mathrm{C} \%$ (wt \%).

The presence of the intermetallic compound $\mathrm{Al}_{2} \mathrm{Zr}$ (Fig. 3, see the gray phase), the amount of which in the composition of the materials under consideration is 2 times lower than the stoichiometric (ie, calculated according to the equilibrium equation), reduces the hardness indices.

Therefore, materials obtained even at high specified values of hot pressing parameters (temperature $\left(1580{ }^{\circ} \mathrm{C}\right)$, pressure of $27 \mathrm{MPa}$, and isothermal holding time up to $26 \mathrm{~min}$ ) have a relatively low level of hardness (up to $\mathrm{HV}_{15}=16.3 \mathrm{GPa}$ ), which excludes consideration of its application as cutting ceramics. It should be noted that the structure of samples obtained from a mixture of $\mathrm{ZrO}_{2}(\mathrm{~m})-18.5 \mathrm{Al}-5.5 \mathrm{C} \%$ (wt \%) also indicates a weak compressibility of the material, which is expressed in the presence of areas with defects in the form of single pores and friability (Fig. 4).Studies of the microstructure of samples obtained at a temperature of $1580^{\circ} \mathrm{C}$ (see Fig. 4 , b) show that even an increase in the hot pressing temperature insignificantly reduces the percentage of structural defects and does not contribute to the production of high-density samples. This, in turn, may be caused by the low aluminum content, which reduces the tendency to compacting the compact both during the melting process and at subsequent stages, due to the viscous and plastic flow of lower-temperature (as opposed to compounds with zirconium and carbon) substances on its basis.

Materials obtained from a mixture of $\mathrm{ZrO}_{2(\mathrm{~m})}-23.5 \mathrm{Al}-5.5 \mathrm{C} \%$ (wt \%) have a relatively defectfree structure, characterized by a fine-grained structure. However, in this case, the phase components are distributed unevenly in the bulk of the materials (see Fig. 5).

Their structure contains areas with accumulations of phases both based on aluminum (Fig. 5, a) and zirconium oxide and carbide (see Fig. 5, b). The latter factor creates a wide range of $\mathrm{HV}_{15}$ and $\mathrm{K}_{1 \mathrm{C}}$ indices (respectively $18,5_{-1,4}^{+0,5}-18,7_{-1,3}^{+0,4} \mathrm{GPa}, 4.3-4.6 \mathrm{MPa} \cdot \mathrm{m}^{-1 / 2}$ ). It should also be noted that the samples hot-pressed at a pressure of $27 \mathrm{MPa}$, according to statistics, have the highest average hardness values (about $18.7 \mathrm{GPa}$ ). However, at the same time, they have a relatively low level of crack resistance, which is probably caused by an increase in the content of the more brittle than the intermetallic phase $\mathrm{ZrC}$, as well as an increase in the content of $\mathrm{Al}_{2} \mathrm{O}_{3}$. 


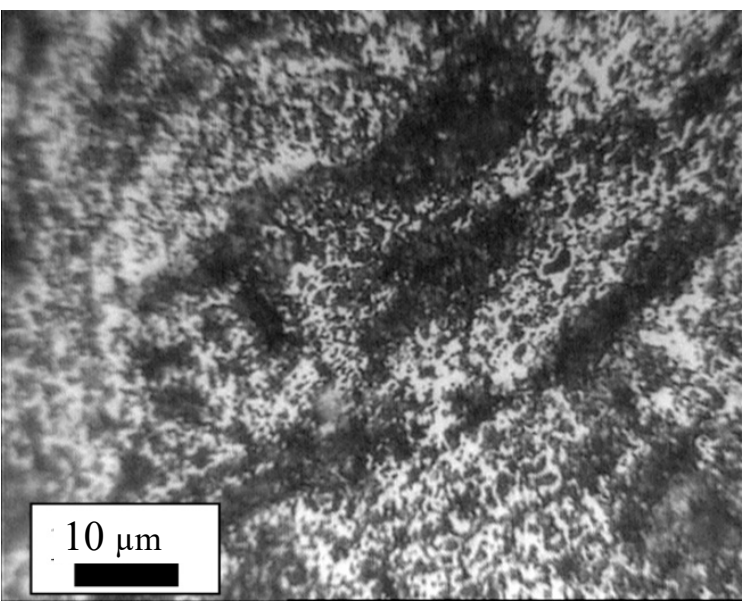

a

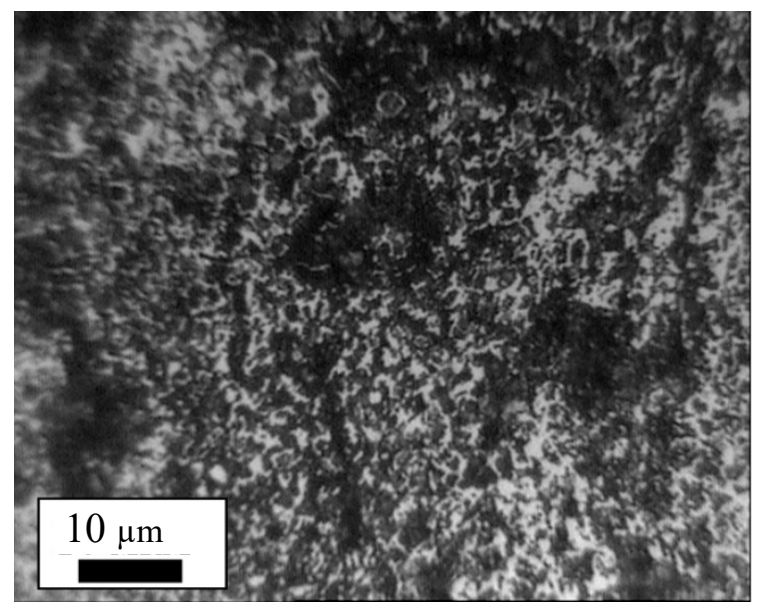

b

Fig. 4. The structure of some materials obtained by hot pressing a mixture of $\mathrm{ZrO}_{2(\mathrm{~m})-}$ $18.5 \mathrm{Al}-5.5 \mathrm{C} \%$ (wt \%), at $\mathrm{P}=27 \mathrm{MPa}$ and $a-T=1460{ }^{\circ} \mathrm{C}, \tau=26 \mathrm{~min} . ; b-T=1580{ }^{\circ} \mathrm{C}$, $\tau=12 \mathrm{~min}$.

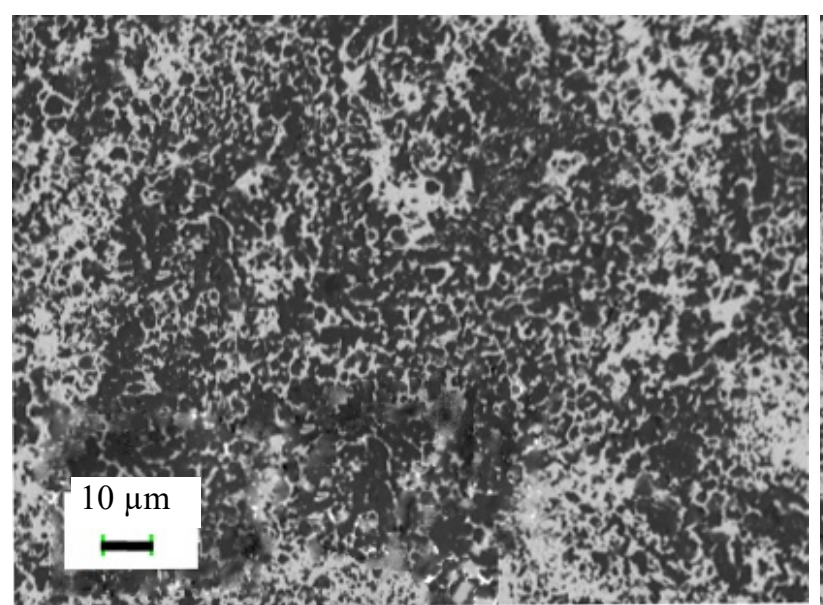

a

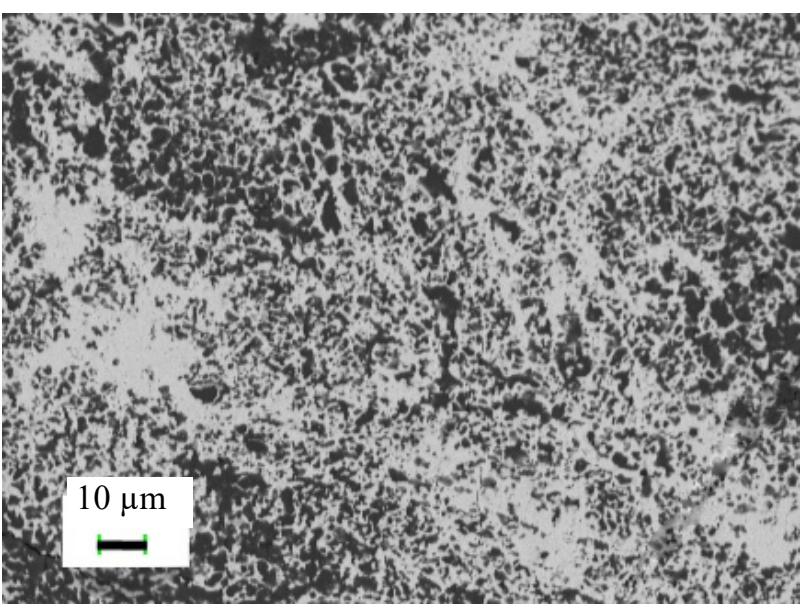

$\mathrm{b}$

Fig. 5. Unevenness of the structure of materials obtained by hot pressing a mixture of $\mathrm{ZrO}_{2}(\mathrm{~m})-$ 23.5Al-5.5C\% (wt \%): a - an accumulation of compounds based on aluminum (dark phase); $b$-accumulation of compounds based on zirconium (light phase).

This is evidenced by a comparison of the structures of the samples of this material (Fig. 6) with those presented in Fig. 3 (where the carbon content in the initial mixture is $3.5 \%$ (wt \%)) and the results of their X-ray microanalysis. A decrease in the amount of intermetallic compound occurs with an increase in the carbon content in the mixture, as a result of their interaction. In contrast to materials obtained from a mixture containing $5.5 \% \mathrm{C}$ (wt \%), the structure of materials with a carbon content of $4.5 \%$ (wt \%) is primarily distinguished by a more uniform distribution of phases in the bulk of the material. 


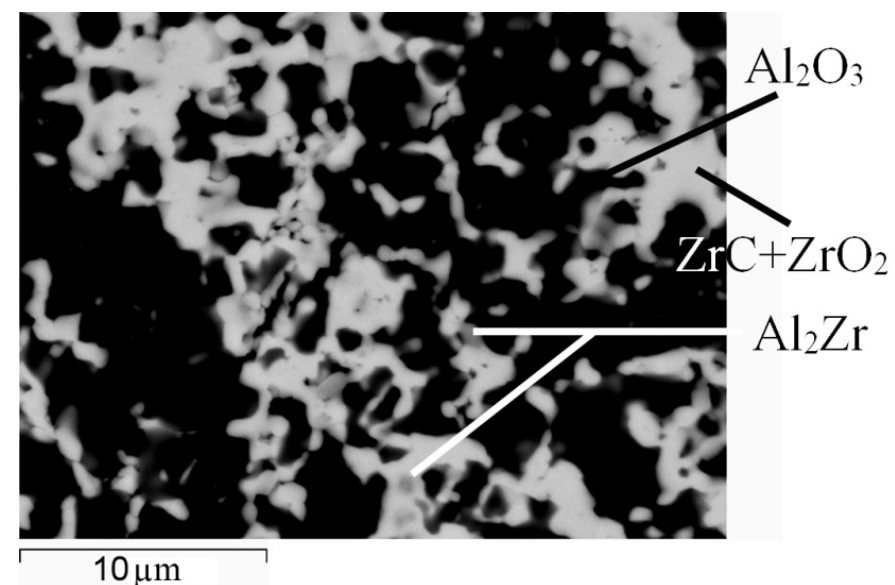

Fig. 6. Microstructure of a thin section in phase contrast (a) of an hot-pressed sample obtained at $T=1580^{\circ} \mathrm{C}, \tau=12 \min , P=27$ $\mathrm{MPa}$ from a mixture of $\mathrm{ZrO}_{2(\mathrm{~m})-}$ $23.5 \mathrm{Al}-5.5 \mathrm{C} \%(w \mathrm{t} \%)$

The low aluminum content in the composition of the initial mixture $\mathrm{ZrO}_{2}(\mathrm{~m})-16 \mathrm{Al}-4.5 \mathrm{C} \%$ (wt \%) leads to poor compressibility of the mixture. The consequence of this is the presence of a small number of single pores in the material obtained from it (see Fig. 7, a). These materials are characterized by very low hardness values (average $\mathrm{HV}_{15}=15.5 \mathrm{GPa}$ ). According to studies [13], a decrease in the amount of aluminum leads to a decrease in the amount of intermetallic compound formed during the interaction of $\mathrm{Al}$ with $\mathrm{ZrO}_{2(\mathrm{~m})}$. This, in turn, reduces the amount of zirconium carbide, which is formed as a result of carbidization of the intermetallic compound, and prevents the growth of the aggregate hardness of the material. The structure of the latter is distinguished by a high content of the $\mathrm{ZrO}_{2(\mathrm{~m})}$ phase (see Fig. 7, b), which has not reacted, which also leads to a decrease in its physicomechanical characteristics.

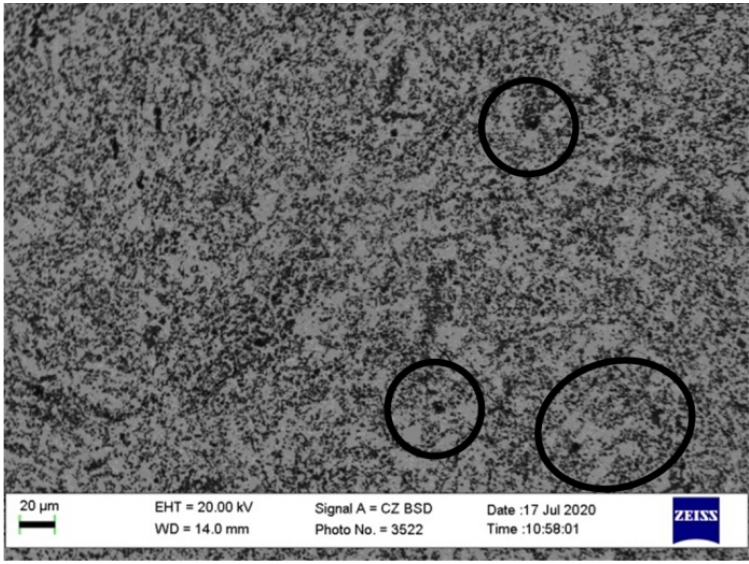

a

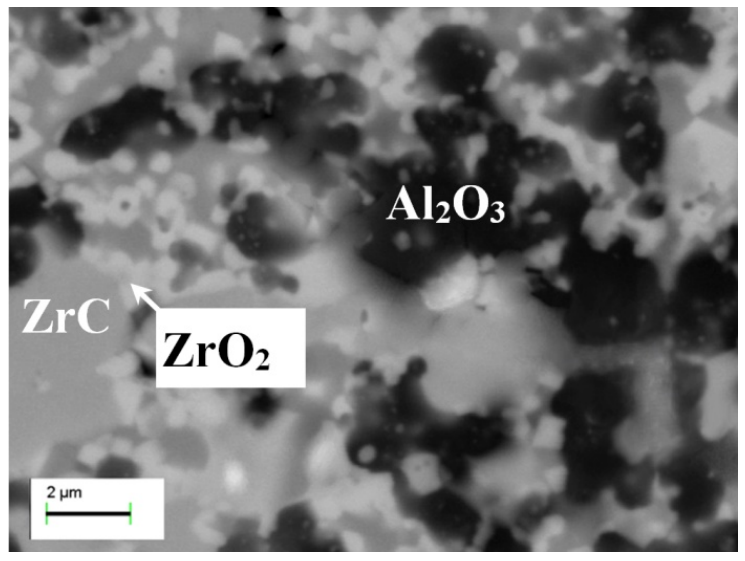

$\mathrm{b}$

Fig. 7. The structure of the material obtained by hot pressing the mixture $\mathrm{ZrO}_{2(\mathrm{~m})-16 \mathrm{Al}-}$ $4.5 \mathrm{C} \%(w t \%)$, at $T=1520{ }^{\circ} \mathrm{C}, \tau=19 \mathrm{~min}, P=24 \mathrm{MPa}: a-$ general view; $b-$ microstructure of a thin section in phase contrast.

Of the entire group of materials containing 4.5\% (wt \%) carbon in the initial mixture, the samples obtained by hot pressing a mixture of $\mathrm{ZrO}_{2(\mathrm{~m})}-21 \mathrm{Al}-4.5 \mathrm{C} \%$ (wt \%) at a temperature of $1520,1640{ }^{\circ} \mathrm{C}$ under pressure of $24 \mathrm{MPa}$ and above, with an isothermal holding time of at least 19 minutes, they have the highest hardness indicators. It should also be noted that, along with high hardness (HV15 = 18.6-18.7 GPa), they have a fairly high level of crack resistance (on average, in the range of 5.7-5.8 $\mathrm{MPa} \cdot \mathrm{m}^{-1 / 2}$ ). Their structure has no defects and an evenly distribution of phases, the range of values of which is within $0.5-2 \mu \mathrm{m}$ (Fig. 8). The even nature of the distribution 
of phase components in the bulk of the material and the absence of defects in the samples shown in Fig. 8 indicates that the pressure and temperature of isothermal holding at the level of $24 \mathrm{MPa}$ and $1520^{\circ} \mathrm{C}$ are sufficient to obtain dense materials from this mixture.

The results of experiments on hot pressing of a mixture of $\mathrm{ZrO}_{2}(\mathrm{~m})-21 \mathrm{Al}-4.5 \mathrm{C}(\% \mathrm{wt} \%)$, at an operating pressure of $18 \mathrm{MPa}$, indicate that this level of compression is insufficient to obtain materials of maximum density. This is indicated by the presence in the structure of the obtained samples of pores (Fig. 9), distributed throughout the volume of the material. The similar structure has a sample obtained at a higher pressure (24 MPa), but a shorter time of isothermal holding (Fig. 9).

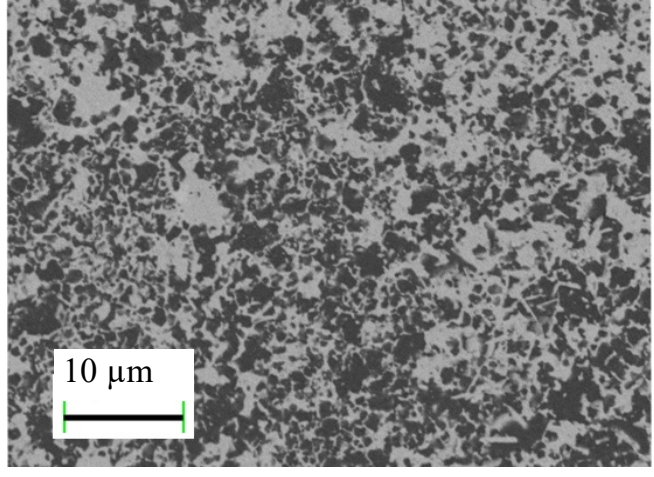

a

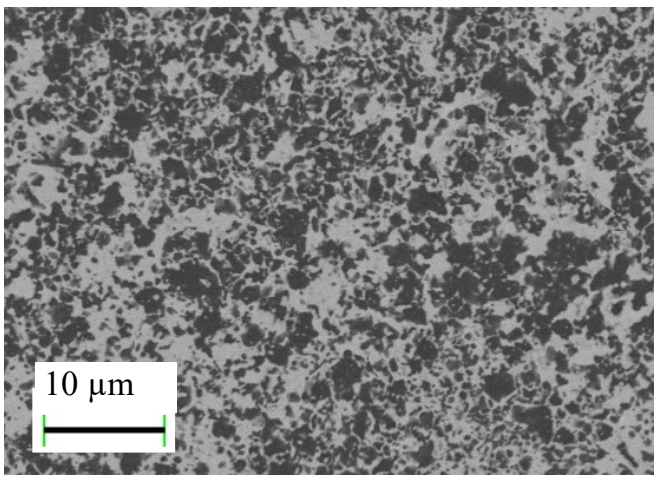

C

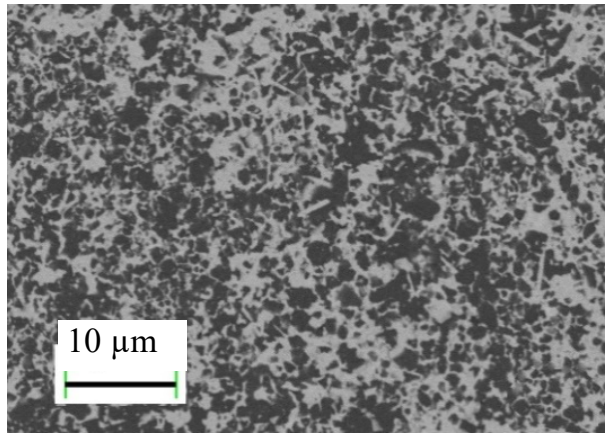

$\mathrm{e}$

$2 \mu \mathrm{m}$

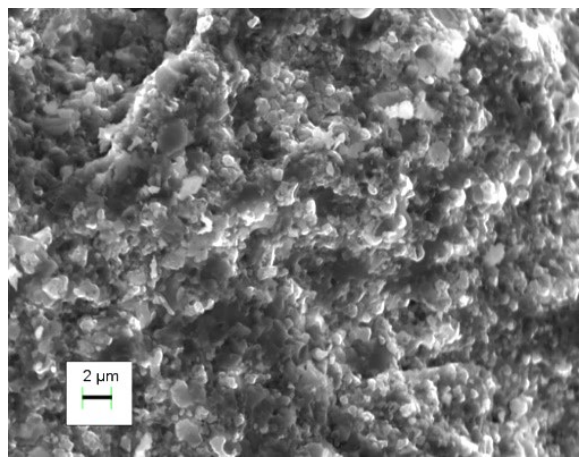

b

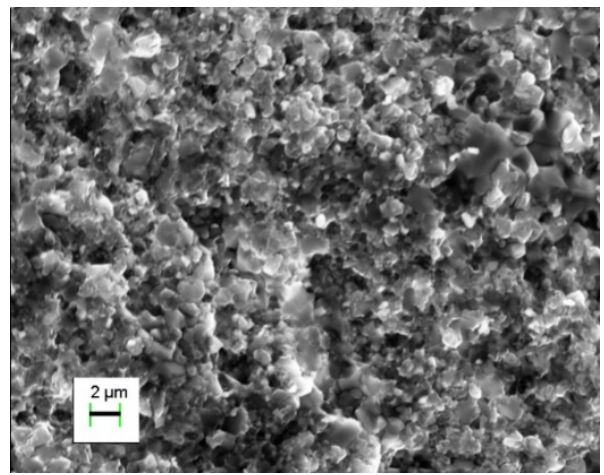

$\mathrm{d}$

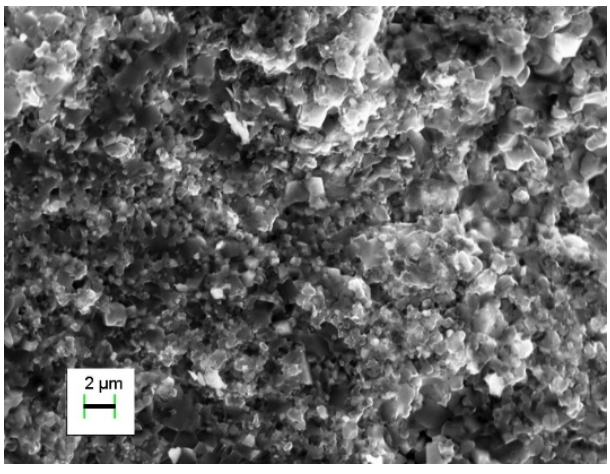

$\mathrm{f}$

Fig. 8. Microstructure in phase contrast $(a, c)$ and fracture surface $(b, d)$ of hot-pressed materials obtained from a mixture of $\mathrm{ZrO}_{2}(\mathrm{~m})-21 \mathrm{Al}-4.5 \mathrm{C} \%$ (wt \%) at a $-\mathrm{T}=1520^{\circ} \mathrm{C}, \tau$ $=19 \min , P=30 \mathrm{MPa} ; b-T=1640^{\circ} \mathrm{C}, \tau=19 \mathrm{~min}, P=24 \mathrm{MPa} ; b-T=1520^{\circ} \mathrm{C}, \tau=$ $19 \min , P=24 \mathrm{MPa}$. 
The content of pores and looseness in such samples is somewhat lower. The presence of residual porosity is probably associated with a short time of isothermal holding, during which the sample does not have time to sufficiently compact due to plastic and viscous flow at the last stage of structure formation. The results of the analysis of the structures and physicomechanical characteristics of the last two samples indicate that a decrease in pressure to $18 \mathrm{MPa}$ has a more significant effect on a decrease in the value of the relative density than a decrease in the isothermal holding time to $5 \mathrm{~min}$. This is reflected in an increase in both the size and the number of pores.

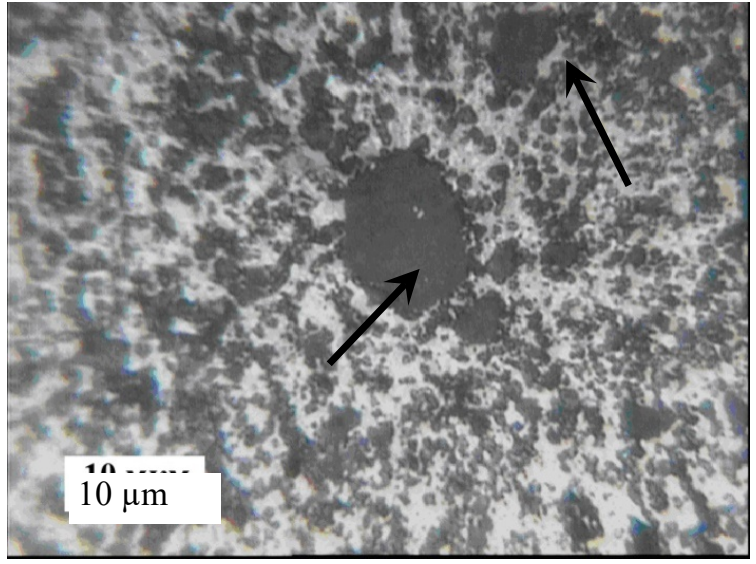

a

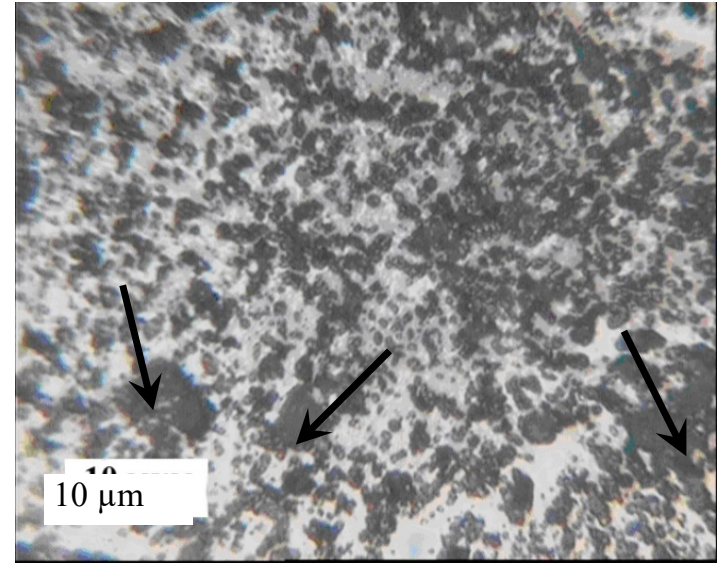

$\mathrm{b}$

Fig. 9. Structure of hot-pressed materials obtained from a mixture of $\mathrm{ZrO}_{2(\mathrm{~m})}-21 \mathrm{Al}-4.5 \mathrm{C} \%$ $(w t \%)$ at $T=1520^{\circ} \mathrm{C}: a-t=19 \min , P=18 \mathrm{MPa} ; b-t=5 \mathrm{~min}, P=24 \mathrm{MPa}$.

So, the analysis of the structures obtained as a result of those carried out according to the planning matrix based on the adopted levels and intervals of variation of factors allows us to draw the following conclusions.

The formation of the structure occurs through a combination of the phase constituent elements of the compounds $\mathrm{Al}_{2} \mathrm{O}_{3}, \mathrm{Al}_{2} \mathrm{Zr}, \mathrm{ZrC}$, formed as a result of the initial charge components interaction, as well as residual $\mathrm{ZrO}_{2(\mathrm{~m})}$.

An increase in the aluminum concentration increases the compressibility of the samples and leads to an increase in the amount of aluminum oxide and intermetallic compounds formed during the interaction of $\mathrm{Al}$ with $\mathrm{ZrO}_{2(\mathrm{~m})}$.

An increase in the carbon content leads to a decrease in the $\mathrm{Al}_{2} \mathrm{Zr}$ content and an increase in the amount of $\mathrm{ZrC}$ in the final material, which in continuous, defect-free zones of the material leads to an increase in the aggregate hardness of hot-pressed materials.

The formation of a defect-free structure of the final material in combination with physical and mechanical characteristics corresponding to cutting mineral ceramics is possible with an optimal combination of the levels of hot pressing parameters $\left(\mathrm{P}=24 \mathrm{MPa}, \mathrm{T}=1520^{\circ} \mathrm{C}, \tau=19 \mathrm{~min}\right)$ and the concentration of the initial components corresponding to the composition of $\mathrm{ZrO}_{2(\mathrm{~m})}-21 \mathrm{Al}-4.5 \mathrm{C}$. They are $18.5 \pm 0.2 \mathrm{GPa}$ and $\mathrm{K}_{1 \mathrm{C}}=5.4 \pm 0.2 \mathrm{MPa} \mathrm{m}^{1 / 2}$. These samples have a continuous defectfree structure, which determines the suitability of using the material for the manufacture of cutting inserts and testing their cutting properties. 


\section{References}

[1] N.Yu. Cherkasova, N.S. Stukacheva, R.I. Kuzmin, E.A. Puris, Development of compositions of aluminum-zirconium ceramics for the manufacture of cutting inserts. / Nanotechnology and Materials Science in Mechanical Engineering. 2019. pp. 347-351.

[2] N.A. Rejab, AZA Ahmad, M.M. Ratnam, Z.A. Ahmad, The effects of $\mathrm{CeO} 2$ addition on the physical, microstructural and mechanical properties of yttria stabilized zirconia toughened alumina (ZTA). Int. Journal of Refractory Metals and Hard Materials 2013; 36; pp. 162-166. https://doi.org/10.1016/j.ijrmhm.2012.08.010

[3] Liu B., C. Huang, X. Lu, M. Gu, H. Liu, In situ growth of TiC whiskers in A12O3 matrix for ceramic machine tools. Ceramics International, 2007, Vol. 33, pp. 1475-1480. https://doi.org/10.1016/j.ceramint.2006.05.015

[4] L. Xikun, Q. Guanming, T. Qu. A12O3-Ti(CN)-Y2O3 composite prepared by HP and its cutting performance. Journal of Rare Earths. Jun. 2007, Vol. 25, pp. 37-41. https://doi.org/10.1016/S1002-0721(07)60519-5

[5] J. Vleugels, Fabrication, wear and performance of ceramic cutting tools. Advances in Science and Technology, 2006, vol. 45, pp. 1776-1785. https://doi.org/10.4028/3-908158-01-x.1776

[6] Q. Dong, Q. Tang, W. Li, A12O3-TiC-ZrO2 nanocomposites fabricated by combustion synthesis followed by hot pressing. Materials Science and Engineering: A. 2008, No 475, pp. 68-75. https://doi.org/10.1016/j.msea.2007.01.158

[7] S.A. Suvorov, I.A. Turkin, M.A. Delovets, Strength of corundum-zirconium materials of microwave synthesis. Materialovedeniye (Materials Science). 2006, № 6, pp. 36-43.

[8] D.E. Clark, D.C. Floz, C.E. Folgar, M.M. Mahmoud, Microwave Solution for Ceramic Engineering. The American Ceramic Society. U.S.A., 2006, P. 494.

[9] K.Z. Gordashnik, A.A. Lebedev, G.K. Kozin, Trends in the creation of ceramic materials and their application in tool production. Instrumentalny svit (Instrumental world). 2007, No. 1 (33), pp. 23-26.

[10]Zhang Guo-Jun, Yang Jian-Feng, Ando Motohide, Ohji Tatsuki, Reactive hot pressing of alumina-silicon carbide nanocomposites. J. Amer. Ceram. Soc. 2004, № 2, pp. 299-301. https://doi.org/10.1111/j.1551-2916.2004.00299.x

[11] J. Zhao, The use of ceramic matrix composites for metal cutting applications. Advances in Ceramic Matrix Composites, 2014, 537-569. https://doi.org/10.1533/9780857098825.3.537

[12] S.I. Dzhelialov, Simulation of the Influence of the Hot-Pressing Parameters and the Mixture Compositions in the $\mathrm{ZrO} 2(\mathrm{~m})-\mathrm{Al}-\mathrm{C}$ System on the Hardness and the Crack Resistance of Ceramics. Inorganic Materials: Applied Research. 2016. Vol. 2 No. 2. 158-162. https://doi.org/10.1134/S2075113316020076

[13] S.I. Dzhelyalov, Interaction of components features of the reaction mixture ZrO2(m)-Al-C systems when heated. IOP Conference Series: Materials Science and Engineering, 2020, 889 (1), 012013. https://doi.org/10.1088/1757-899X/889/1/012013

[14] S.N. Dub, A.L. Maistrenko, A.A. Isakov, Peculiarities of Ceramic Crack Resistance Measurement by Indentation Method. Zavodskaya laboratoriya (Factory laboratory), 1993, No. 4, pp. 58-60. 